\title{
Errors in Construction of Facilities in Restricted Conditions
}

\section{Sokolov NS*}

Chuvash State University, Russia

*Corresponding author: Sokolov NS, Chuvash State University, Russia.

Published Date: June 14, 2021

\begin{abstract}
The construction of facilities in cramped conditions requires a special approach to the need to develop and implement measures to ensure the safe operation of the buildings surrounding the building within the limits of geotechnical influence. Builders often neglect the impact of the new facility technology on the possible negative effects (cracks on facades due to uneven precipitation, heels, etc.) of the buildings in use. The term «minimum price» is still used when part of a building is erected below zero. This approach completely disregards the notion of «technical utility». At the same time the builders go to any tricks to reduce the cost. This «irrational» way of construction may eventually result in a substantial increase in the cost of constructing a zero part of a building and, as a general rule, in a longer construction period (agreement on a new project as a result of substitution of another geotechnical technology, passing of new construction expertise). This article examines one negative case from the geotechnical practice of constructing 16 storey dwellings next to an existing five-storey dwelling house.
\end{abstract}

Keywords: Geotechnical construction; Irregular precipitation; Ground anchors; Excavation fencing; Electrical discharge technology; EDT piles

\section{Introduction}

Construction in cramped conditions is the most problematic from the point of view of the technology of construction production of parts below zero mark. Design and construction should include a set of measures to ensure the safe operation of existing buildings. Modern geotechnical technologies are successful in meeting such challenges [1-13]. This article discusses a negative example of the construction of a multi-storey apartment building next to an existing house.

\section{Methods and Materials}

The new construction facility is a single cast-in-place reinforced concrete block in the shape of a rectangle. The above-ground part of the construction facility consists of a technical floor and 16 aboveground floors. The structural scheme is a cast-in-situ concrete-free frame with self-supporting outer walls of foam-concrete blocks supported by inter-story floors. The ceilings and coatings are made of cast-in-situ reinforced concrete. The structural solution of the foundation is provided as a cast-in-place reinforced concrete foundation plate. The depth of the foundation pit varies from 9.3 $\mathrm{m}$ to $9.6 \mathrm{~m}$ in various areas. The absolute level of the bottom of the foundation pit is $175.30 \mathrm{~m}$ of the Baltic Normal Height System (BAS). The width of the foundation pit is $27.0 \mathrm{~m}$, and its length is $40.0 \mathrm{~m}$. In accordance with para. 9.36 SP 22.13330.2011 "Updated edition of SNIP 2.02.01-83* "Soil bases of buildings and structures" the radius of the new construction impact zone is equal $r_{36}=4 \cdot H_{K}$ for a pit to be excavated with steel pipe fencing. Thus, the impact zone for the specific case was $38.4 \mathrm{~m}$. A five-story two-access apartment building is located in the area. The technical condition category of the adjacent residential building according to the reports on the results of the technical inspection carried out shall be considered 
satisfactory according to the existing regulatory documents. The spatial stiffness of the apartment house is ensured by hard disks of inter-level floors and coatings, blocks of staircases. In plan the object has dimensions of $54.0 \times 12.75 \mathrm{~m}$ and $17.0 \mathrm{~m}$ in height. The foundations are made of prefabricated tapes made of concrete blocks of FBS basement walls $400-500 \mathrm{~mm}$ thick laid on a cast-inplace reinforced concrete belt erected on the foundation slabs of the FL. Foundation depth varies from 2.79 to $3.05 \mathrm{~m}$. The walls of the building are made of silicate brick $510.0 \mathrm{~mm}$ thick on cementsand solution. The inner load-bearing walls, $380.0 \mathrm{~mm}$ thick, are also made of silicate brick, and the inter-story and attic floors are made of reinforced concrete multi-hollow slabs $220.0 \mathrm{~mm}$ thick. In the initial version, the foundation walls of the foundation pit are designed as an unfastened sheet pile wall using two tiers of Atlant ground anchors (Figure 1A).

For this case, steel pipes with a cross section of $530 \times 8$ by GOST
10704-91 "Electrically welded steel line-weld tubes. Schedule" with a step of $1.0 \mathrm{~m}$ are used for the sheet wall, and pipes with a direction of "Z" are arranged with a step of $0.8 \mathrm{~m}$. They are also filled with heavy concrete in the immediate vicinity of the building. Top of sheet pile wall tubes elevation is assumed variable from $184.54 \mathrm{~m}$ to $184.84 \mathrm{~m}$ (BAS). The bottom of the pipe fencing along the axes " 1 ", " $\mathrm{A}$ " and " 12 " is located at the elevations from 171.54 to $171.84 \mathrm{~m}$ BS with their length of $13.0 \mathrm{~m}$, along the axis " $\mathrm{Z}$ " bottom of the pipe fencing stands at $166.84 \mathrm{~m}$ (BAS) with pipe length of $18.0 \mathrm{~m}$. A board fence $40.0 \mathrm{~mm}$ thick is designed between the pipes of the fence. At the request of the developer customer, we (LLC FORST Research and Production Company) have been instructed to develop an alternative variant of the unfastened sheet pile wall using steel pipes of the same cross-section dimensions but using ground anchors of three tiers of prepared using electric-discharge technology (EDT anchor) (Figure 1B).

A)

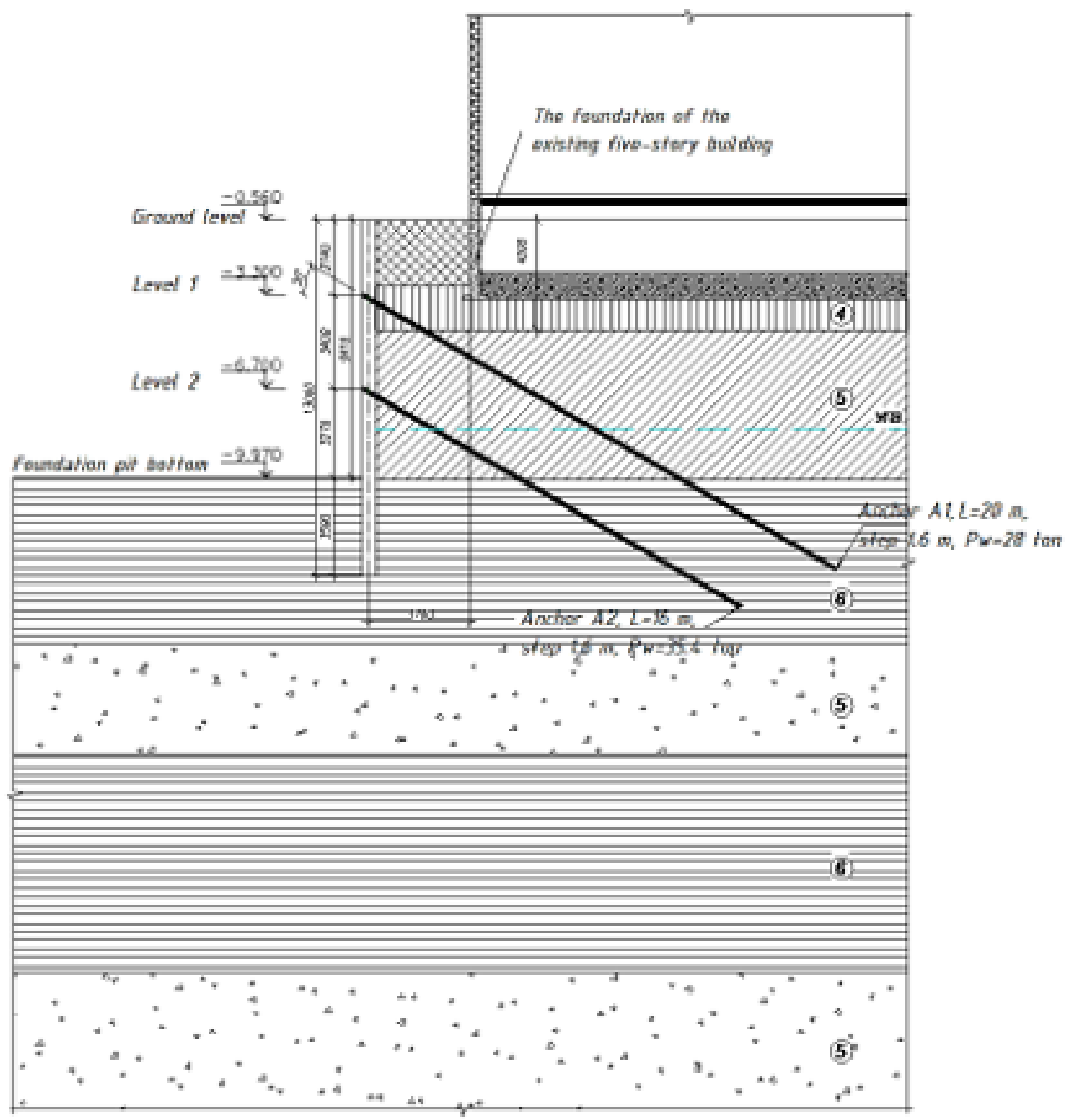


B)

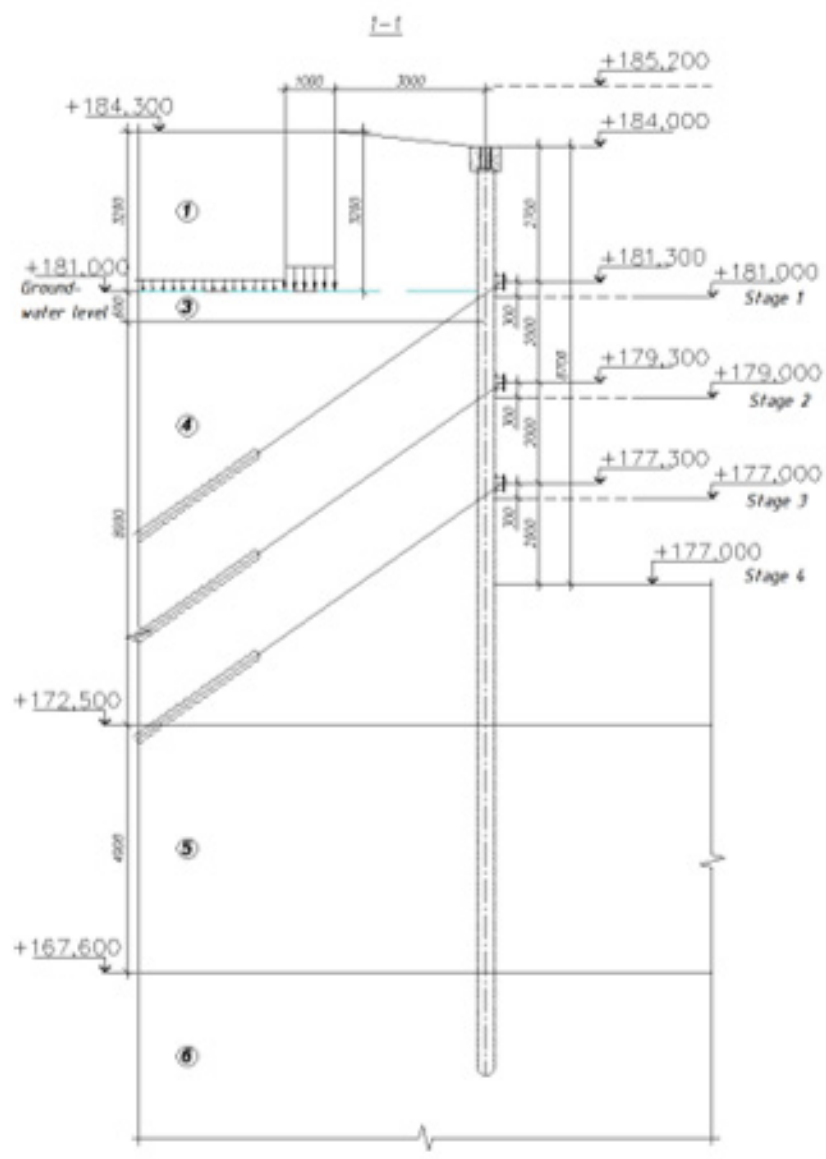

Figure 1: Variants for unfastened sheet-pile fencing made of steel pipes and with the help of ground anchors: A) «Atlant» anchors; B) EDT anchors.

The design burial depth of the steel pipes was deeper than the original design. In addition, we have designed sheet pile wall using drilled injection EDT piles with a diameter of $350 \mathrm{~mm}$ with a cast-in-situ reinforced concrete girder on the top of the piles at the adjoining areas to the existing buildings. The planned wall is a solid cast-in-place reinforced concrete structure that would prevent the soil from sloughing under the foundations of the existing apartment building during excavation.

\section{Results and Discussion}

The customer having studied both variants of the fence of the pit has come to an unexpected and strange conclusion about the necessity of cheaper design of the pit fence. In this case, the meaning of "technical feasibility" is completely neglected, although economic efficiency is significantly acquired. Thus, they were ordered a third version of the pit fencing project, but without anchoring, using, as in previous designs, steel pipes and steel shootings on two levels to replace the ground anchors. At the same time, the developed project excludes the construction of a solid sheet pile wall (it is one of the main buried structures ensuring the foundation stability under the foundations of an existing residential house) on the site of attachment to the existing residential house. A 50B2 double-stranded spreader belt is designed to treat soil forces evenly and to offend them. It should be noted that used steel pipes were used as the construction material for the shootings. When they are executed at one level only. The used firing pipes suffered significant deformations (bends, cross-sectional collapses, as well as soil and asphalt holes) during the rupture of the foundation pit, which resulted in horizontal deformations of the sheet pile wall made of steel pipes towards the pit. At the same time, the absence of solid barrier sheet walls at the areas of connection to the existing apartment building during excavation of the foundation pit caused the soil to fall out from under the foundation footing. As a result, the existing dwelling house was immediately vertically deformed, as evidenced by the deformation cracks that appeared on the outer surfaces of the facades, progressing in time. The urgently organized geotechnical monitoring of the vertical movements of sediment marks (Figures $2 \& 3$ ) confirmed the worst fears. A part of the dwelling house on the side of the new construction of the settlement and continues to deform (Figure 4). The client urgently decided to develop a project for cementing the deformed part of the 
foundation and immediately implement it (Figure 4). Geotechnical monitoring results show that even after the geotechnical work for cementing the foundation, foundation deformations continued to develop. All the maximum allowable strains have already been exceeded. For example, the most deformed sediment grade received a vertical displacement of $52.0 \mathrm{~mm}$ (Figure 5) at an allowable value of $20.0 \mathrm{~mm}$. In order to avoid further deformation of the existing dwelling house, the customer again requested us (LLC NPF FORST) to develop a project for reinforcement of the deformed base and performance of geotechnical works for its reinforcement. Electrodischarge geotechnical technology for arrangement of drilling- injection piles (EDT piles) was used as the most suitable for solving problems in restricted conditions. Only by strengthening the foundations of the troubled dwelling house using this geotechnical technology has it been possible to prevent further deformations of the foundation, as shown by 1) geotechnical forecast and 2) results of geotechnical monitoring of vertical movements of sediment marks. Table 1 below shows the steps from the beginning of construction to the resolution of the issues on strengthening the foundation of the deformed five-story apartment building (Table 1) (Figure 2-5).

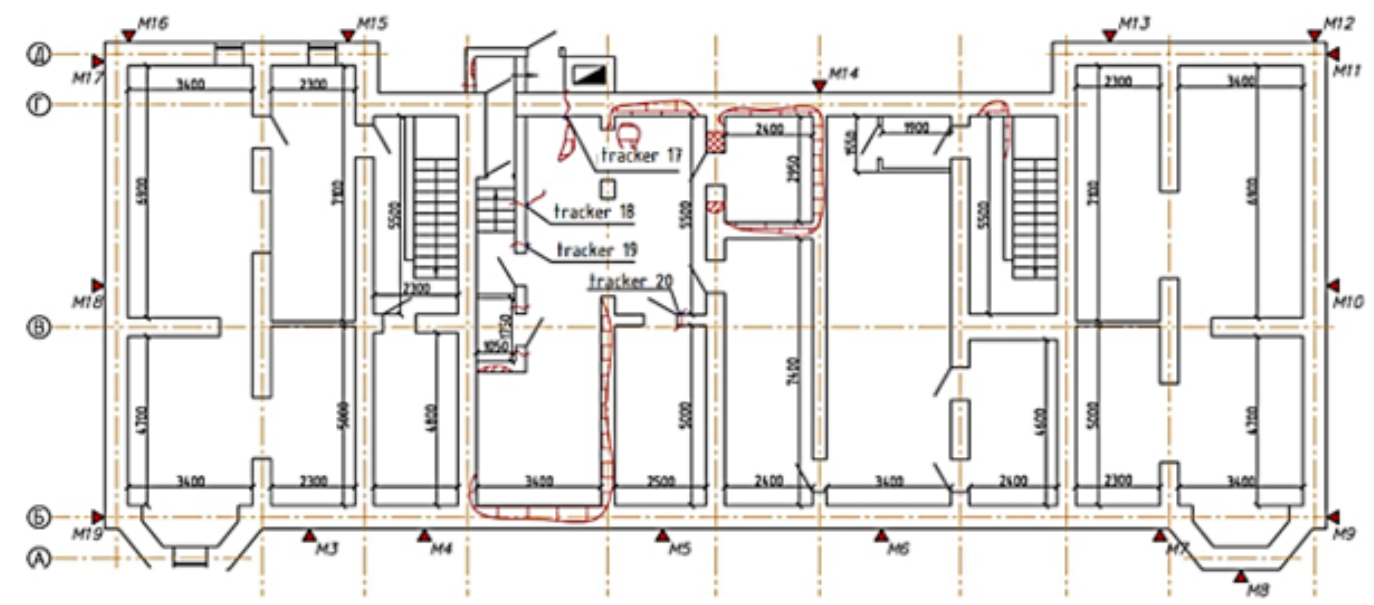

Figure 2: A typical floor plan for a five-story apartment building with a sediment grade scheme 1-25.

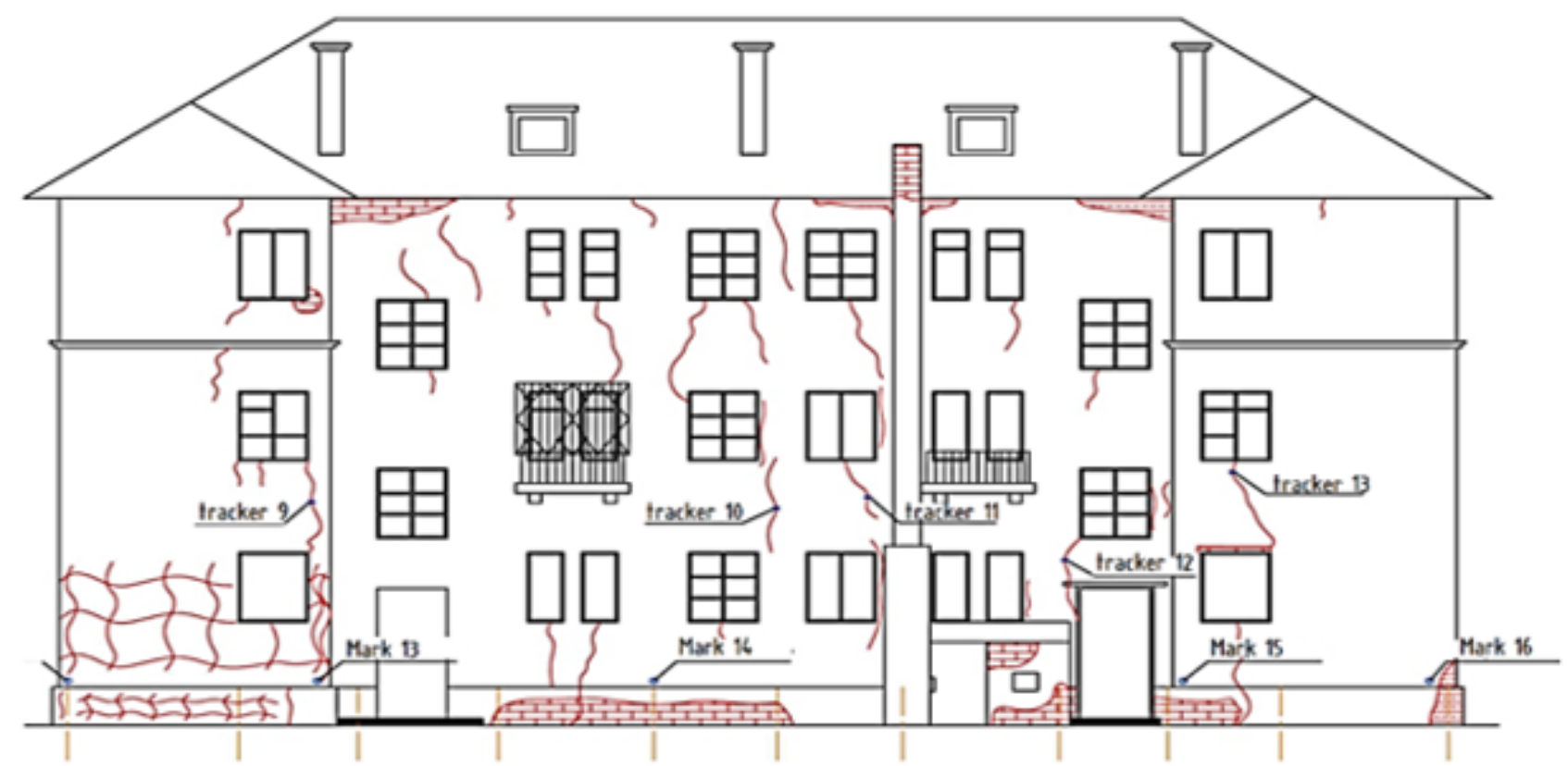

Figure 3: Front facade of the five-story apartment building with indication of deformation cracks. 


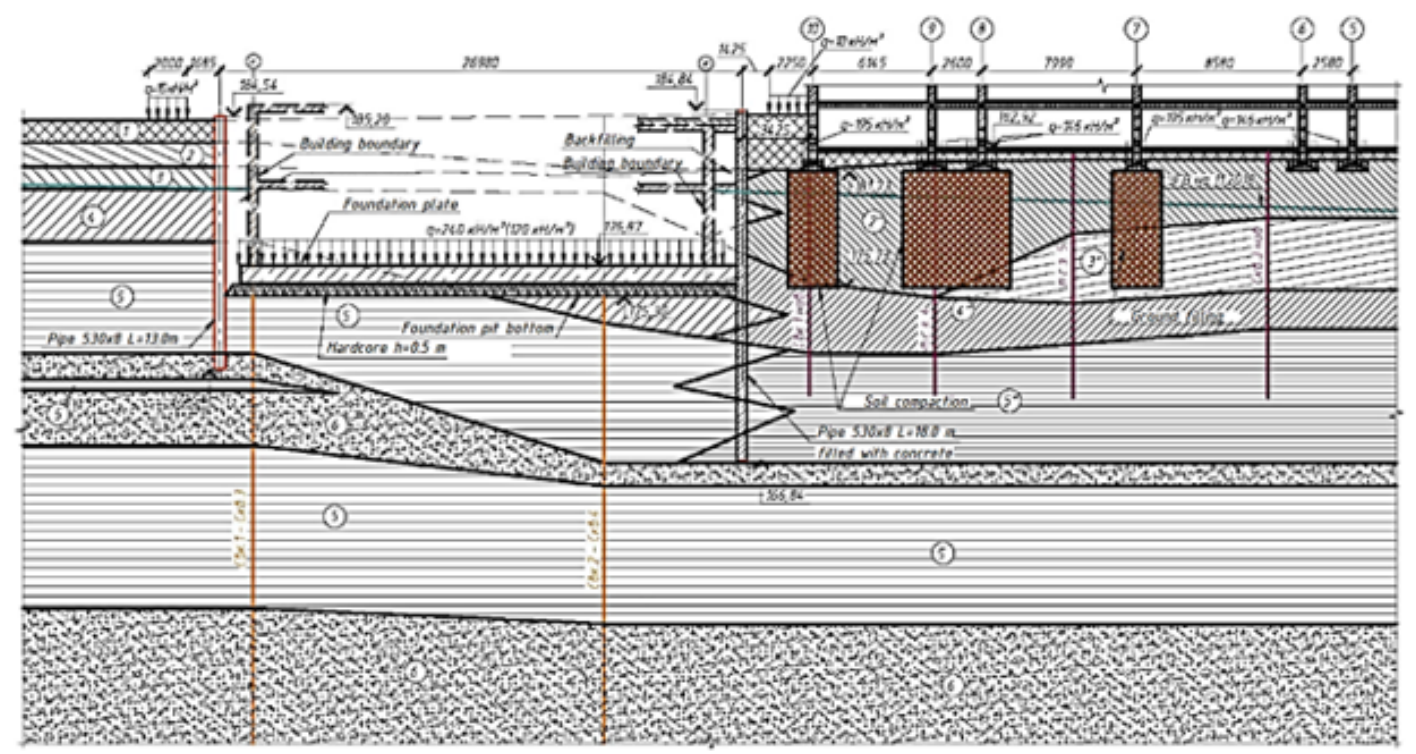

Figure 4: The vertical tie-in of the object under construction and the cementing of the base of existing building No. 1 into the engineering and geological section.

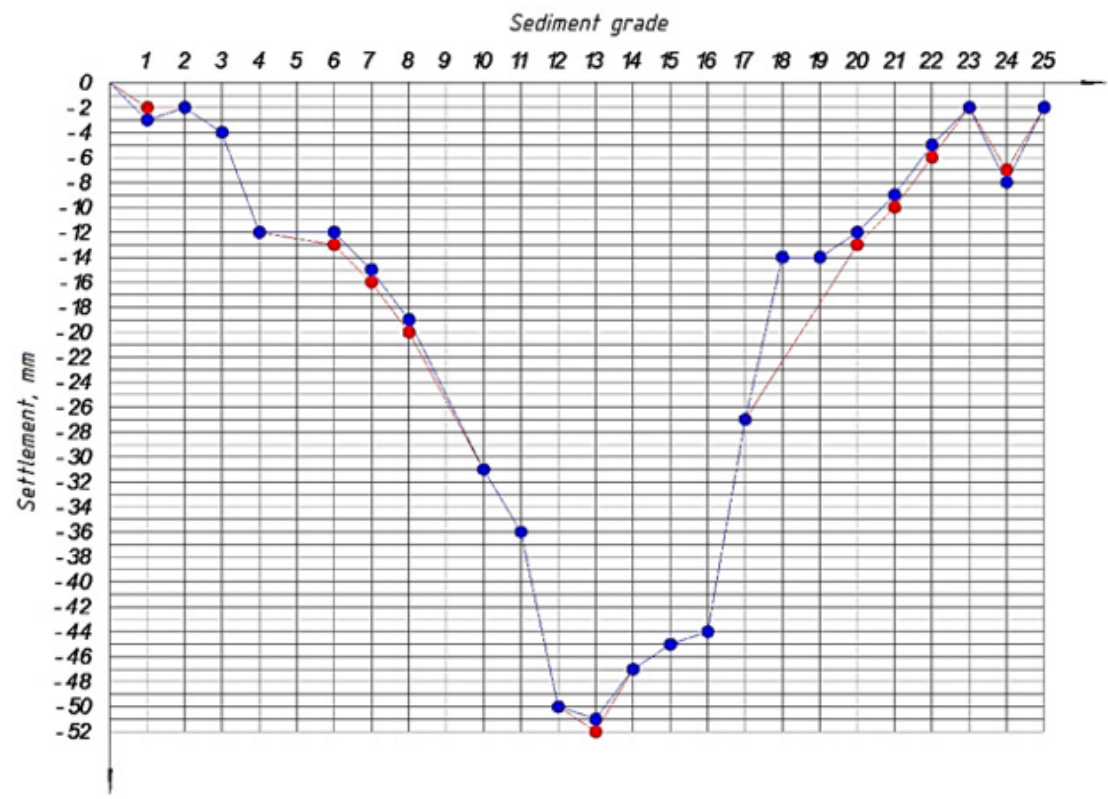

Figure 5: Deposition schedule of strain marks installed around the existing house: 1-25 - sediment grades.

\section{Conclusion}

1. In geotechnical construction in restricted conditions, disregard of the principle of "technical feasibility" in favor of achieving economic efficiency in most cases leads to impairment of the operational reliability of existing buildings and structures.

2. The so-called "economic efficiency" acquired may be substantially reduced to zero, or the final design of the pit fence may end up being much more expensive than the original design. Construction terms are guaranteed to be extended.

\section{Acknowledgement}

None.

\section{Conflict of Interest}

No conflict of interest.

\section{References}

1. Mangushev RA, Nikiforova NS, Konyushkov VV, Osokin AI (2013) Design and construction of underground structures in open pits. DIA, Moscow.

2. Mangushev RA, Veselov AA, Konyushkov VV, Sapin DA (2012) Numerical modeling of technological precipitation of neighboring buildings in the 
device trench wall in the ground II Bulletin of civil engineers 5(34): 87 98.

3. Makovetsky OA, Zuev SS, Khusainov II, Timofeev MA (2014) Ensuring geotechnical safety of the building under construction. Housing construction 9: 34-38.

4. Ilichev VA, Konovalov PA, Nikiforova NS, Bulgakov LA (2004) Deformations of the Retaining Structures Upon Deep Excavations in Moscow. Proc. Of Fifth Int. Conf on Case Histories in Geotechnical Engineering, pp.5-24.

5. Ilyichev, VA, Nikiforova NS, Koreneva EB (2007) Computing the evaluation of deformations of the buildings located near deep foundation tranches. Proc. of the XVIth European conf. on soil mechanics and geotechnical engineering. Madrid, Spain, Geo-technical Engineering in urban Environments 2: 581-585.

6. Nikiforova NS, Vnukov (2011) DA Geotechnical cut-off diaphragms for built-up area protection in urban underground development. The pros of the 7thI nt. Symp. Geotechnical aspects of underground construction in soft ground, tc28 IS Roma, AGI No:157 NIK.

7. Nikiforova NS, Vnukov DA (2004) The use of cut off different types as a protection measure for the existing buildings at the nearby underground pipeline's installation. Proc of Int Geotech Conf dedicated to the Year of Russia in Kazakhstan, pp.338-342.

8. Petrukhin VP, Shuljatjev OA, Mozgacheva OA (2003) Effect of geotechnica work on settlement of surrounding buildings at underground construction. Proceedings of the $13^{\text {th }}$ European Conference on Soil Mechanics and Geotechnical Engineering. Prague.

9. Th. Triantafyllidis, Schafer R (2007) The Impact of diaphragm wall construction on the stress state in soft ground and serviceability of adjacent foundations. Proceedings of the $14^{\text {th }}$ European Conference on Soil Mechanics and Geotechnical Engineering, 2: 683-688.

10. Ponomarev AB (2015) Geotechnical monitoring of a house. Housing construction 9: 41-46.

11. Sokolov NS, Viktorova SS, Fedorova TG (2014) Piles of increased bearing capacity. Materials of the 8 th all-Russian ( $2^{\text {nd }}$ International) conference New in architecture, design construction renovation, pp.411-415.

12. Sokolov NS, Rabinow VM (2016) Technology of the piles increased the bearing capacity Housing construction 9: 11-14.

13. Sokolov NS (2016) Technological methods devices bored piles with multiple caps. Housing construction. 10: 54-59.

14. Sokolov NS (2018) Ground Ancher Produced by Electric Discharge Technology, as Reinforsed Concrete Structure. Scopus-Key Engineering Materials, pp.76-81

15. Sokolov NS (2018) Use of the Piles of Effective Type in Geotechnical Construction. Scopus-Key Engineering Materials, pp.70-74.

16. Sokolov NS (2018) One of Geotechnological Technologies for Ensuring the Stability of the Boiler of the Pit. Scopus-Key Engineering Materials, pp.56-69.

17. Sokolov NS (2018) Regulated injection pile-electric discharge technology with multiple pile enlargements posed as an underground reinforced concrete structure with a controlled load capacity. 18 international multidisciplinary scientific GeoConference SGEM 2018 Albena Resort SPA Bulgaria, pp.601-608. 